\title{
Equal Rights for General Internists
}

\author{
Eileen E. Reynolds, $M D^{7}$, Joseph $L i, M D^{2}$, and James Heffernan, $M D, M P H^{3}$ \\ 'Division of General Medicine, Beth Israel Deaconess Medical Center (BIDMC), Boston, USA; ${ }^{2}$ Section of Hospital Medicine, Division of General \\ Medicine, BIDMC, Boston, USA; ${ }^{3}$ Section of Primary Care, Division of General Medicine, BIDMC, Boston, USA.
}

$\mathrm{J}$ Gen Intern Med 34(2):172

DOI: $10.1007 / \mathrm{s} 11606-018-4721-2$

() Society of General Internal Medicine 2018

I $\mathrm{t}$ was with disappointment that we read "Equal Rights for General Internists?" by JGIM co-editor (and our colleague at BIDMC) Carol Bates. ${ }^{1}$ The lack of time and support for scholarly work by clinician generalists is an important topic for discussion. We agree with Dr. Bates, "No question that academic hospitalists could benefit from more protected time to boost their scholarship." We also share her opinion that outpatient generalists need more protected time for academic work. However, we disagree with several of her other opinions, including:

1. "Outpatient generalists are in greater need for protected time than their inpatient colleagues."

2. "Those in hospital and ICU medicine... how much time is truly needed for recovery...time required for recuperation...may be substantially less than the time allotted..."

3. "Double standard exists for our clinical faculty who have essentially no protected time in comparison with those who have days or weeks that are free of clinical responsibilities."

We encourage all faculty members to be respectful of each other's challenges. We do not find it productive or reasonable to question the amount of rest necessary for any individual amidst the demands of their job. While we agree with Dr. Bates that the clinical job descriptions for primary care and hospital medicine are organized differently, the total number of hours spent by our full-time hospital medicine and primary care internists on clinical work is quite comparable.

"Equal rights" implies one group is treated unfairly. With pressure to enhance numbers of patients seen, electronic records that lead both primary care and hospital medicine providers to chart during "off" hours, and the rapidly expanding ranks of highly clinical "academic" faculty to provide service rather than scholarship or education, general internists of all types have little time, support, or incentive to pursue scholarly work. Primary care and hospital medicine should be working together to enhance the academic environment. Dr. Bates' editorial instead pits these two groups against each other, vying for the pool of "existing protected time."

Finally, we disagree vehemently that a "double standard" exists. We hold all of our faculty members to the same academic standards with respect to any part of their job descriptions.

Corresponding Author: Eileen E. Reynolds, MD; Division of General MedicineBeth Israel Deaconess Medical Center (BIDMC), Boston, USA (e-mail: ereynold@bidmc.harvard.edu).

Compliance with Ethical Standards:

Conflict of Interest: The authors declare that they do not have a conflict of interest.

\section{REFERENCES}

1. Bates CK. From the Editors' Desk: Equal Rights for General Internists. J Gen Intern Med 33(5):575. 